\title{
Anionic Polysaccharides From Phototrophic Microorganisms Exhibit Antiviral Activities to Vaccinia Virus
}

\author{
Aleksandar Radonić 1 , Stefanie Thulke², John Achenbach ${ }^{1}$, Andreas Kurth ${ }^{1}$, Anna Vreemann'1, Tanja König ${ }^{3}$, Christian Walter ${ }^{3}$, Kurt \\ Possinger $^{2}$, Andreas Nitsche ${ }^{1 *}$
}

${ }^{1}$ Centre for Biological Security 1, Robert Koch-Institut, Berlin, Germany

${ }^{2}$ Oncology - Hematology, Charité - Universitätsmedizin Berlin, Berlin, Germany

${ }^{3}$ Institute of Bioprocess Engineering, Universität Erlangen-Nürnberg, Germany

\begin{abstract}
The aim of the present study was to characterise anti-vaccinia virus activities of anionic exopolysaccharides TK V3 isolated from cyanobacterium Arthrospira platensis and an exopolysaccharide isolated from the rhodophyt Porphyridium purpureum, respectively. These substances have previously been shown to be active against other enveloped viruses. We determined the in vitro inhibition of GFP-expressing vaccinia virus replication of $50 \%$ at a concentration of $0.65 \mu \mathrm{g} /$ $\mathrm{ml}$ for EPS and of $0.78 \mu \mathrm{g} / \mathrm{ml}$ for TK V3. Substances also had an antiviral effect against ectromelia virus which is a most distinct orthopoxvirus genetically and the causative agent of mousepox. Anti-vaccinia virus and anti-ectromelia virus activities were demonstrated to increase with decreasing multiplicity of infection. Furthermore, non-toxic reduction of vaccinia virus in ovo replication was shown. Using time-of-addition assays, inhibition of viral entry by polyanionic substances was verified. EPS and TK V3 derived from phototrophic microorganisms represent novel anti-orthopoxvirus substances.
\end{abstract}

Keywords: Vaccinia virus; Antiviral; Anionic polysaccharides; Microalgae; Cyanobacteria

Abbreviations: CaSp: Calcium Spirulan; DENV: Denguevirus; DS: Dextran Sulfate ; EPS: Sulphur-Containing Exopolysaccharide from P. purpureum p; GFP: Green Fluorescent Protein; HCMV: Human Cytomegalovirus; HSV: Herpes Simplex Virus; MW: Molecular Weight; P. I.: Post Infectionem; RSV: Respiratory Syncytial Virus; OPV: Orthopoxvirus; sPS: Sulfated Polysaccharides; TK V3: Sulphur-Containing Exopolysaccharide from A. Platensis; VACV : Vaccinia Virus

\section{Introduction}

Vaccinia virus (VACV) belongs to the orthopoxvirus (OPV) genus and is closely related to variola virus, the causative agent of smallpox. The virions are generally enveloped, contain a double-stranded DNA and replicating within the cytoplasm. VACV represents the prototype of the OPV genus and had been successfully used as vaccine against smallpox which was declared eradicated in 1979 [1]. However, due to the severe adverse effects caused in a considerable proportion of vaccinees, vaccination was halted soon after eradication. Today, in the light of a decreasing immunity in the population, the potential abuse of variola virus for bioterrorist purposes is intensively discussed [2]. Therefore, and with regard to the increasing number of zoonotic infections, the development of strategies to counteract OPV infections by introducing new therapeutic and prophylactic measures is widely accepted [3].

Sulfated polysaccharides (sPS), in particular dextran sulfate (DS) and related polyanionic compounds, have been shown to be active against various viruses since the 1960ies [4]. Interest in these compounds increased when first studies on anti-human immunodeficiency virus (HIV) activities were published $[5,6]$. Most of the studies on the antiviral activity of polyanionic compounds, as well as their mode of action, were performed by De Clercq and co-workers [7]. Today it is known that the crucial factors for antiviral activity beside the scaffold of a polymer (saccharides, alkyls, aminoacids etc.) and the type of anion (sulfate, sulphone, carboxylate, phosphate) - are mainly the molecule size, its conformation, charge frequency or charge spreading [9]. It is generally assumed that polyanionic compounds interact with positively charged viral membrane glycoproteins of enveloped viruses and thereby inhibit initial viral attachment to negatively charged heparan sulfate proteoglycans on the cellular membrane [8]. Referring to VACV, the interaction between A27L membrane gene product and heparan sulfate was revealed by Chung et al.[10]. Concerning HIV and influenza A virus, further specific interactions between sPS and the viral membrane have been elucidated in detail (reviewed by Witvrouw et al. [7] and Luscher-Mattli [9].

Aside from their favored antiviral activities, sPS exhibit several undesirable side effects, like anticoagulant activity and the induction of severe but reversible thrombocytopenia when applied intravenously [11]. Both effects depend on the compound structure. To overcome these side effects and isolate improved antiviral compounds, we aimed to isolate novel antiviral sPS from phototrophic microorganisms.

Phototrophic microorganisms provide a large pool of bioactive compounds, and the intensive search for new drugs leads to the identification and structure determination of many novel compounds from these organisms $[12,13,14]$. Gustafson and co-workers described antiviral activities of sulphoglycolipides isolated from cyanobacteria for the first time $[14,15]$. In addition to sulphoglycolipides $[14,15,16,17,18]$, to date lectins $[19,20,21,22,23,24]$ and sPS have been discovered to exhibit antiviral activities against HIV-1, HIV-2, human cytomegalovirus (HCMV), herpes simplex virus types 1 and 2 (HSV-1 and HSV-2), denguevirus types 2, 3 and 4 (DENV-2, DENV-3

*Corresponding author: Andreas Nitsche, Centre for Biological Security 1, Robert Koch-Institut, Nordufer 20, 13353 Berlin, Germany, Tel: +49 3018754 2313; Fax: +49 30 18754 2605; E-mail: nitschea@rki.de

Received November 11, 2010; Accepted December 28, 2010; Published January 03, 2011

Citation: Radonić A, Thulke S, Achenbach J, Kurth A, Vreemann A, et al. (2010) Anionic Polysaccharides From Phototrophic Microorganisms Exhibit Antiviral Activities to Vaccinia Virus. J Antivir Antiretrovir 2: 051-055. doi:10.4172 jaa. 1000023

Copyright: (c) 2010 Radonić A, et al. This is an open-access article distributed under the terms of the Creative Commons Attribution License, which permits unrestricted use, distribution, and reproduction in any medium, provided the original author and source are credited. 
and DENV-4), respiratory syncytial virus (RSV), measles virus, mumps virus, influenza A virus and other enveloped viruses.

Recently, we have isolated anionic, sulphur-containing exopolysaccharides from Porphyridium purpureum (EPS) and Arthrospira (formerly Spirulina) platensis (TK V3). TK V3 is different from TK V2 which presumably contains the already known sPS calcium spirulan (CaSp) that is intracellularly produced [25]. CaSp has previously been described to possess antiviral activities against HIV1, HCMV, HSV-1, measles virus, mumps virus and influenza A virus $[26,27,28]$ TK V3 was shown to inhibit replication of HIV, HCMV, HSV-1, human herpesvirus type 6 (HHV-6) and VACV, but not the enveloped viruses Epstein-Barr virus and influenza A virus [25] EPS isolated from $P$. purpureum displays antiviral activities against HCMV, HHV- 6 and VACV [31]. The study presented here was performed to investigate in detail anti-VACV activities of EPS and TK V3 in vitro and in ovo and to gain insight into the mode of anti-VACV action.

\section{Material and Methods}

\section{Antiviral substances}

TK V2 (intracellular product from cyanobacterium $A$. platensis NIES 39 and presumably containing the already known CaSp), TK V3 (extracellular product from $A$. platensis) and EPS (extracellular product from the rhodophyt $P$. purpureum) were produced and structurally described as previously reported $[31,32]$. Briefly, TK V2 and TK V3 were isolated from culture supernatant by centrifugation of culture broth, lyophilization and dialysis against deionized ultrapure water. EPS extraction was performed using chloroform, methyl alcohol and Butanol, followed by cross-flow ultrafiltration with deionized ultrapure water, and the extract was finally lyophilised. Other extracts isolated according to the same procedure displayed no antiviral activity (data not shown). DS (MW 500,000) was used as antiviral reference.

\section{Cells and viruses}

HEp-2 cells (ATCC: CCL-23) were cultured in D-MEM (Gibco, Paisley, UK) supplemented with 5\% foetal bovine serum (PAN Biotech $\mathrm{GmbH}$, Aidenbach, Germany) and 1\% L-Glutamine (PAA, Pasching, Austria). VERO C1008 cells (ATCC: CRL-1586) were cultured in D-MEM containing $10 \%$ foetal bovine serum and $1 \%$ L-Glutamine. All cells were maintained in a humidified environment with $5 \% \mathrm{CO}_{2}$ at $37^{\circ} \mathrm{C}$, and confluent cells were seeded at the ratio of $1: 4$ into new culture flasks. VACV strain NYCBOH was obtained from ATCC (VR-1536). Ectromelia virus (ECTV) strain Nu-1 was obtained from Hermann Meyer, Institute of Microbiology, Bundeswehr (Federal Armed Forces), Munich, Germany. Recombinant VACV-expressing green fluorescent protein (VACV-GFP) was obtained from Rafael Blasco, Departamento de Sanidad Animal, Centro de Investigacion en Sanidad Animal-INIA, Madrid, Spain. Virus strains were propagated in HEp-2 cells at a multiplicity of infection (MOI) of 0.25 . Infected cells were incubated for 4 days until a distinct cytopathic effect (CPE) was observed. Supernatants containing viral particles and infected cells were harvested by centrifugation $(10 \mathrm{~min}$ at $1000 \mathrm{x} \mathrm{g})$ after freeze thawing. Supernatants were titrated and stored at $-75^{\circ} \mathrm{C}$ until use.

\section{Cell proliferation tests}

5000 HEp- 2 cells were seeded as described above in $100 \mu \mathrm{l}$ medium per well in a 96-well plate and grown for 24 hours. Subsequently, medium was replaced by $100 \mu \mathrm{l}$ of antiviral substance dilution which was tested 8-fold in parallel. Substances were incubated at cell growth conditions for 48 hours. Following removal of supernatant and cell treatment with $10 \mu \mathrm{l}$ of trypsin/EDTA $(0.08 / 0.13 \%)$ for $5 \mathrm{~min}, 100 \mu \mathrm{l}$ medium and $10 \mu \mathrm{l}$ WST-1 reagent (Roche, Penzberg, Germany) were added. Reaction was incubated for 4 hours and finally dye extinction was measured at $450 \mathrm{~nm}$.

\section{Infection in 96-well plates}

$5 \times 10^{3}$ cells in $100 \mu \mathrm{l}$ medium per well were incubated in a humidified environment with $5 \% \mathrm{CO}_{2}$ at $37^{\circ} \mathrm{C}$. After 24 hours, supernatant was removed and cells were infected and treated with different concentrations of substances from phototrophic microorganisms. A final volume of $100 \mu \mathrm{l}$ per well was adjusted. 24 hours (VACV), 30 hours (ECTV) and 48 hours (VACV-GFP) p. i., respectively, medium was removed and stored at $-20^{\circ} \mathrm{C}$ to perform a plaque titration assay later on. The proportion of infected cells was calculated after immunofluorescence staining.

\section{Plaque assay}

$1.2-1.5 \times 10^{6}$ VERO C1008 cells were seeded in $200 \mu \mathrm{l}$ medium per well of a 24 -well plate. Serial dilutions $\left(10^{-1}-10^{-6}\right)$ of $200 \mu \mathrm{l}$ viruscontaining cell culture supernatants were applied in quadruplicate. Infection occurred at $37^{\circ} \mathrm{C}$ for $4-5$ hours and was terminated by overlaying of $400 \mu \mathrm{l}$ of carboxymethyl cellulose (BDH Ltd., Poole, UK). Cells were cultured for 4 further days, subsequently fixed with $4 \%$ formaldehyde for $20 \mathrm{~min}$, stained with $0.1 \%$ naphthalene black solution $(1.7 \% \mathrm{w} / \mathrm{v}$ Naphthol Blue Black [Sigma-Aldrich, Munich, Germany] and $22.7 \% \mathrm{w} / \mathrm{v}$ sodium acetate in absolute acetic acid) for $15 \mathrm{~min}$ and finally washed with water. Plaques within the naphthalene black cell layer were counted per well.

\section{Immunofluorescence staining}

Cells were fixed with $200 \mu \mathrm{l}$ formaldehyde $(4 \%)$ for $20 \mathrm{~min}$, subsequently treated with $70 \mu \mathrm{l}$ Triton X-100 (0.2\% in PBS) for $15 \mathrm{~min}$, afterwards incubated with $50 \mu \mathrm{l}$ human anti-pox antibody (Omrigam; Omrix. Biopharmaceutics Ltd, Givat Shmuel, Israel), 1:500 in diluent buffer [PBS, $2 \% \mathrm{BSA}, 0.2 \% \mathrm{NaN}_{3}$ ] for 1 hour and eventually stained with $50 \mu \mathrm{l}$ FITC-conjugated goat anti-human IgG (Caltag Laboratories, Burlingame/CA, USA, 1:50 in diluent buffer containing $200 \mathrm{ng} / \mathrm{ml}$ Evan's Blue) for 1 hour. All incubations were performed at room temperature, and between each step cells were thoroughly, but carefully, washed with PBS. Volumes of reagents are indicated per well. Regarding VACV-GFP-infected cells, only counterstaining was performed using $50 \mu \mathrm{l}$ Evan's Blue $(200 \mathrm{ng} / \mathrm{ml})$ for $10 \mathrm{~min}$. To determine the ratio of infected cells, representative pictures were taken, and infected and non-infected cells were quantified using the Wright cell imaging facility ImageJ software (National Institutes of Health, Toronto, Canada). The inhibitory substance concentration, causing a $50 \%$ decrease of viral replication $\left(\mathrm{IC}_{50}\right)$, was determined by plotting the ratio of infected cells per well against the substance concentration used and calculated using the equation of a quadratic smoothing function.

\section{In ovo tests}

Fertile eggs from hens of the breed White Leghorn were incubated at $37.7^{\circ} \mathrm{C}$ and a relative humidity of $50-60 \%$ under forced air circulation. Before inoculation on day 11, eggs were candled to eliminate infertile eggs and dead embryos. Approximately $50 \mu \mathrm{l}$ of VACV (100 PFU) and $50 \mu \mathrm{l}$ of antiviral compound $(5 \mu \mathrm{g} / \mathrm{mL})$ were inoculated simultaneously onto the chorioallantoic membrane (CAM) $[29,30]$. Embryos were incubated at $37^{\circ} \mathrm{C}$, examined daily for signs of mortality and sampled when the positive control (VACV injection only) caused embryos' death. Four days after infection, chick embryo 
livers and CAMs were removed and homogenized in $1 \mathrm{~mL}$ growth medium. Aliquots were processed for standard plaque assay.

\section{Statistics}

General calculations were performed with Microsoft Excel. Statistical analysis was performed with SPSS.

\section{Results}

\section{Substance-induced cytotoxicity}

Initially, the in vitro cytotoxicities of TK V3, EPS as well as DS were determined. For this purpose, HEp-2 cells were treated with each substance for 48 hours and the mitochondrial dehydrogenase activity was quantified using WST-1 reagent which directly correlates to cellular proliferation. DS as antiviral reference did not exhibit any cytotoxic activity at concentrations of up to $50 \mu \mathrm{g} / \mathrm{ml}$. TK V3 from $A$. platensis and EPS from $P$. purpureum were not cytotoxic in concentrations of up to $500 \mu \mathrm{g} / \mathrm{ml}$ (data not shown).

\section{Antiviral in vitro activity}

Antiviral activities of TK V3, TK V2 and EPS against VACVGFP were determined by estimating the ratio of infected cells 48 hours p. i. Figure 1 shows the decrease of the viral load with the concentrations of TK V3, EPS and DS, respectively. The $\mathrm{IC}_{50}$ were calculated to be $0.78 \mu \mathrm{g} / \mathrm{ml}$ for TK V3, $0.65 \mu \mathrm{g} / \mathrm{ml}$ for EPS and $1.24 \mu \mathrm{g} /$ $\mathrm{ml}$ for DS. TK V3 and EPS did not achieve complete viral inhibition up to concentrations of $10 \mu \mathrm{g} / \mathrm{ml}$, and DS did not achieve complete viral inhibition up to concentrations of $5 \mu \mathrm{g} / \mathrm{ml}$. TK V3 and EPS also highly and TK V2 weakly inhibited replication of unlabeled VACV as determined by plaque reduction assay 24 hours p. i. (data not shown).

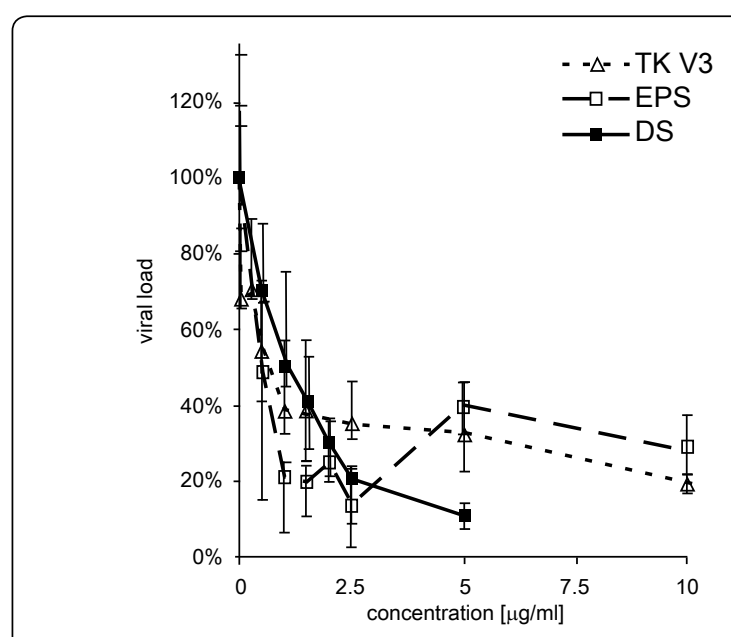

Figure 1: Antiviral activities of EPS from $P$. purpureum and TK V3 from A. platensis against VACV-GFP 48 hours $p$. i. Viral load is given in percent of the maximum number of infected cells in the positive control without antiviral substance to the number of infected cells in substance-treated cultures; $\mathrm{MOI}=0.1$ (mean values of $n=4$ ).

\begin{tabular}{|l|l|l|l|l|}
\hline & \multicolumn{4}{|l|}{ Viral load [\%] } \\
\hline \multirow{2}{*}{ Virus } & Cells & Positive control & $\begin{array}{l}10 \mu \mathrm{g} / \mathrm{ml} \\
\text { TK V3 }\end{array}$ & $\begin{array}{l}10 \mu \mathrm{g} / \mathrm{ml} \\
\text { EPS }\end{array}$ \\
\hline \multirow{2}{*}{ VACV-GFP } & HEp-2 & 68 & 24 & 20 \\
\cline { 2 - 5 } & VERO C1008 & 74 & 27 & 54 \\
\hline \multirow{2}{*}{ ECTV } & HEp-2 & 3 & 1 & 1 \\
\cline { 2 - 5 } & VERO C1008 & 9 & 3 & 2 \\
\hline
\end{tabular}

Viral load is given in percent of infected cells related to total cell number. Mean values of $n=4$.

Table 1: Antiviral activities of TK V3 from A. platensis and EPS from $P$. purpureum.
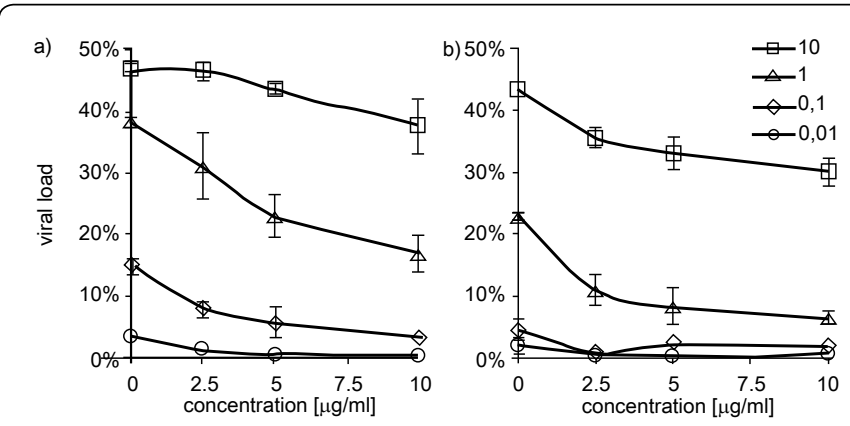

Figure 2: Antiviral activities of TK V3 from $A$. platensis (a) and EPS from $P$ purpureum (b) against VACV-GFP of varying MOI $48 \mathrm{~h}$ p. i. Viral load is given in percent of infected cells related to total cell number. (Mean values of $n=4$.).

Table 1 demonstrates that the antiviral activities of the substances derived from phototrophic microorganisms are not restricted to the HEp-2 host cell type and VACV, but are also detectable in VERO C1008 host cells infected with a distant relative of VACV, the ectromelia virus. TK V3 acts comparably against VACV-GFP and ECTV in HEp-2 and VERO C1008 cells. Interestingly, EPS activity against VACV-GFP in VERO C1008 cells ( $20 \%$ vs. positive control of $68 \%$ ) is reduced compared to HEp-2 cells ( $54 \%$ vs. positive control of $74 \%$ ). Even if the overall infection rates for ectromelia are low, resulting in marginal differences for extract-treated cells, the data represent a trend that underlines the antiviral effect of the extracts used in VACV infection.

To determine the number of infectious virus particles produced by infected cells in the presence and absence of inhibitory substances, VERO C1008 cells were infected with VACV and the proportion of infected cells analysed 48 hours p.i. In addition, the respective supernatants were used for titre determination by plaque test. The number of primary infected cells as well as the number of infectious virus particles found in the supernatant were decreased by TK V3 and EPS, respectively, in a concentration-dependent manner (data not shown).

Furthermore, the antiviral activities of TK V3 and EPS against VACV-GFP were analysed in relation to the applied MOI. Figure 2 illustrates the strong antiviral activities of TK V3 and EPS even for high amounts of virus. Even using high $\mathrm{MOI}=10$, broad antiviral activities were observed, with a reduction of about $20 \%$ (TK V3) and $30 \%$ (EPS), respectively, at concentrations of $10 \mu \mathrm{g} / \mathrm{ml}$ of both antiviral substances. Substance activity against ECTV in HEp-2 and VERO C1008 cells also correlated with MOI (data not shown).

\section{Antiviral in ovo activity}

The CAM of embryonated eggs was treated with EPS and TK V3 and was simultaneously infected with VACV. Four days p. i. embryo vitality (candling) and viral load of CAM and liver extracts (plaque assay) were determined, respectively. In contrast to untreated and infected embryos, the substance-treated and infected embryos were vital even after 4 days p. i. Figure 3 demonstrates the pronounced decrease of viral load (>90\%) within the CAM of TK V3- or EPS-treated eggs as determined by plaque titration. Viral hepatic replication was decreased by $50 \%$ and $70 \%$, respectively. Except for non-infected controls treated with substance only, all embryos were dead after 7 days p. i. These data indicate low substance toxicities.

Of note, in contrast to non-infected and substance-treated embryonated eggs, infected and substance-treated deceased embryonated eggs smelled of hydrogen sulphide and developed green 
discolorations. It is conceivable that these effects might occur due to the high sulphur content of substances derived from phototrophic microorganisms which might be reduced to hydrogen sulphide and further react to green iron sulphide in non-vital organisms.

\section{Mode of action}

As already mentioned, sPS were shown to act by inhibition of the viral entry process by blocking viral membrane glycoproteins. In order to reveal the mode of antiviral action of the substances derived from phototrophic microorganisms, we performed time-of-addition assays. As demonstrated in Figure 4, substances acted best when antiviral treatment and infection were performed simultaneously (bars B) compared to untreated infections (grey bars, A). Lowest antiviral activities were determined when antiviral treatment had occurred p. i. (bars C). Good antiviral activities were also detected when antiviral treatment was carried out prior to infection (bars D), but substances possessed less antiviral activities if they had been removed before infection (bars E). These results demonstrate that the investigated substances do not interact with cells but with free viral particles, which corresponds to the theory about the mode of antiviral sPS action. This theory is supported by the observation that the virus spread at MOI $<0.1$ appeared not to be random via free virus in the cell culture supernatant, but occurred mainly from cell to cell.

\section{Discussion}

Our data indicate that anionic exopolysaccharides

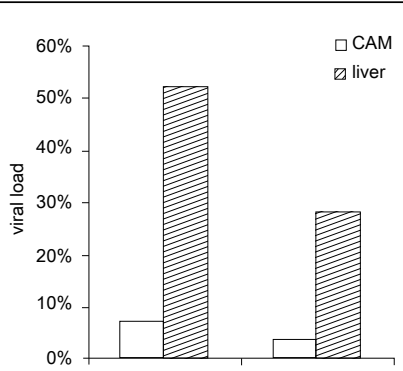

Figure 3: Antiviral in ovo activities of $0.25 \mu \mathrm{g} \mathrm{TK} \mathrm{V3} \mathrm{from} A$. platensis and $0.25 \mu \mathrm{g}$ EPS from $P$. purpureum against VACV in CAM and liver of chick embryos 4 days p. i. Infection and substance application occurred simultaneously on CAM. Viral load was determined by plaque assay and is given in percent of the untreated infection per CAM or liver extract as mean of $n=2$.

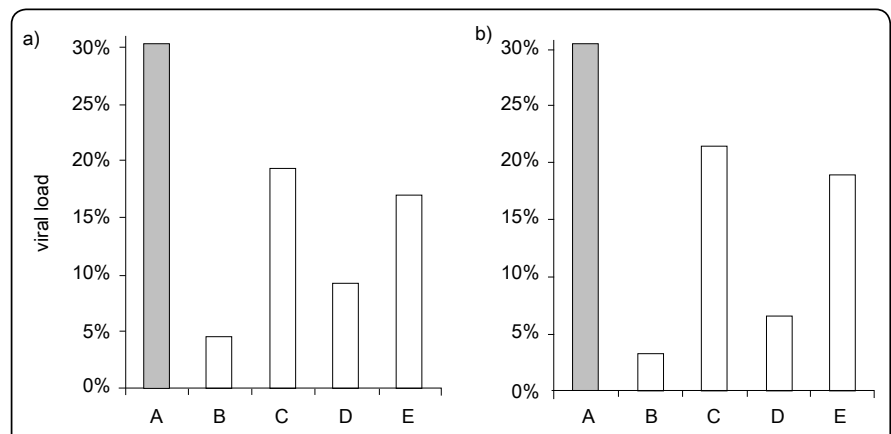

Figure 4: Variation of the time of addition of $5 \mu \mathrm{g} / \mu \mathrm{l}$ TK V3 from A. platensis (a) or $5 \mu \mathrm{g} / \mu$ l EPS from $P$. purpureum (b) concerning the time point of VACV-GFP infection. A: infection without treatment, B: simultaneous infection and antiviral treatment, C: antiviral treatment 60 min p. i., D: antiviral treatment 60 min prior to infection, E: antiviral treatment for $60 \mathrm{~min}$ followed by removal of antiviral reagent prior to infection. Viral load is given in percent of infected cells related to total cell number. Bars represent mean values of $n=4$.
TK V3 from cyanobacterium A. platensis and EPS from rhodophyt P. purpureum possess anti-OPV activities. TK V3 had been shown to be also active against HCMV, HHV-6, HIV-1 and HSV-1 [31,32] and EPS had already been demonstrated to inhibit HCMV and HHV6 replication [31]. Using recombinant GFP-expressing VACV, we determined $\mathrm{IC}_{50}$ values against VACV of $0.78 \mu \mathrm{g} / \mathrm{ml}$ (TK V3) and $0.65 \mu \mathrm{g} /$ $\mathrm{ml}$ (EPS), respectively, compared to $1.24 \mu \mathrm{g} / \mathrm{ml}$ (DS, MW 500.000). Hence, compared to DS, the antiviral activity is slightly higher for the substances derived from phototrophic microorganisms. The $\mathrm{IC}_{50}$ determined for DS is significantly lower than that observed by other workgroups, e.g. $\mathrm{IC}_{50}=40 \mu \mathrm{g} / \mathrm{ml}$ [7], which might be explained by differently used virus strains (wild type/GFP-expressing strain) and host cell systems (primary rabbit kidney cells/HEp-2 cells). WST1 tests did not reveal any inhibition of HEp-2 cell proliferation by TK V3 or EPS up to a concentration of $500 \mu \mathrm{g} / \mathrm{ml}$ and up to $50 \mu \mathrm{g} / \mathrm{ml}$ for DS. Thus, the selectivity indices (SI) for VACV in HEp-2 cells can be estimated to be $\mathrm{SI}>640$ for TK V3, SI $>770$ for EPS and $\mathrm{SI}>40$ for DS, respectively. Irrespective of the initial $\mathrm{MOI}$, the substances were also active against VACV and ECTV in HEp-2 and VERO C1008 cells. Even using a high MOI of 10 , substances were shown to inhibit the VACVGFP replication in a concentration-dependent manner. Furthermore, TK V3 and EPS were marginally toxic for embryonated eggs and decreased VACV in ovo replication. Thus, the substances are suitable for in vivo application in further experiments.

As generally accepted, anionic polysaccharides show antiviral activity against enveloped viruses whose initial cellular receptors are anionic (sulfated) carbohydrates. They act via inhibition of viral membrane glycoproteins [7]. Accordingly, the mechanism of the antiVACV action of TK V3 and EPS may be attributed to the inhibition of the binding of virus to cells (Figure 4). The results showed that the highest antiviral effect can be observed when performing antiviral treatment and infection at the same time. The second highest antiviral effect was detected by preincubation of virus with the TK V3 and EPS. This can be attributed to the concentration changes that occur when preincubated antivirals and virus are added to cells. Like all chemical processes, this is an equilibrium reaction. The concentration changes may lead to a decrease of the anionic polysaccharides on the virus membrane for a short time and may allow better virus interaction with the cells before the reaction reaches an equilibrium. This antiviral mode of action is completely different from that of other known anti-VACV drugs, e.g. Cidofovir, Ribavirin, ST-246 or Gleevec, which opens the possibility of combinatory therapies and makes further investigation into TK V3 and EPS anti-VACV activities advisable.

Intracellular anionic polysaccharide TK V2 from A. platensis presumably contains the already known CaSp which was shown to be active against various enveloped viruses in vitro, for example HSV-1, HIV-1, HCMV, measles virus and influenza A virus [26,33]. Surprisingly, TK V2 which is highly active against HIV-1, HSV-1, HCMV and HHV-6 in vitro [32], is not active against VACV-GFP up to a concentration of $250 \mu \mathrm{g} / \mathrm{ml}$ and only weakly inhibitory of VACV strain $\mathrm{NYCBOH}$ replication. Possibly, disparities in the activities against different viruses as well as different VACV strains might be caused by single specific variations within viral membrane glycoproteins.

Anionic polysaccharides derived from phototrophic microorganisms represent a novel substance group featuring various antiviral activities [7,34]. Here we demonstrated the antiviral activities of two sulphur-containing anionic exopolysaccharides from cyanobacterium $A$. platensis (TK V3) and from rhodophyt $P$. purpureum (EPS) against the OPV VACV and ECTV.So far, there have been few reports of anti-OPV polyanionic activities derived from phototrophic microorganisms $[8,35]$. 
Production of the compounds in monoseptic cultures of microalgae and cyanobacteria occurred in photo-bioreactors and can be scaled up successfully [36]. Ionic polysaccharides can easily be extracted from culture broth, avoiding extensive separation from and elimination of cellular components. From our experience with this method, the whole process is highly reproducible. These aspects favour further steps towards the development of the compounds as potential therapeutic agents.

\section{Conclusion}

Our data suggest that anionic polysaccharides TK V3 and EPS from phototrophic microorganisms are novel inhibitors of OPV and other enveloped viruses. Their in vivo efficacies and bio-availabilities as well as their toxicity profile upon systemic and topical application have to be studied further. However, anionic polysaccharides may be considered for combinatorial treatment with already established antiviral substances.

\section{Acknowledgements}

The authors are grateful to Ursula Erikli for copy-editing.

\section{References}

1. Fenner F, Henderson DA, Arita L, Jezck Z, Ladnyi LD (1988) Smallpox and Its Eradication. World Health Organization, Geneva, 1476pp.

2. Belongia EA, Naleway AL (2003) Smallpox vaccine: the good, the bad, and the ugly. Clin Med Res 1: 87-92.

3. Sliva K, Schnierle B (2007) From actually toxic to highly specific--novel drugs against poxviruses. Virol J 4: 8 .

4. Bengtsson S (1965) Mechanism of dextran sulfate inhibition of attenuated poliovirus. Proc Soc Exp Biol Med 118: 47-53.

5. Nakashima H, Yoshida O, Tochikura TS, Yoshida T, Mimura T, et al. (1987) Sulfation of polysaccharides generates potent and selective inhibitors of human immunodeficiency virus infection and replication in vitro. Jpn J Cancer Res 78:1164-1168.

6. Ueno R, Kuno S (1987) Dextran sulphate, a potent anti-HIV agent in vitro having synergism with zidovudine. Lancet 1: 1379.

7. Witvrouw M, De Clercq E (1997) Sulfated polysaccharides extracted from sea algae as potential antiviral drugs. Gen Pharmacol 29: 497-511.

8. Witvrouw M, Este JA, Mateu MQ, Reymen D, Andrel G, et al. (1994) Activity of a sulfated polysaccharide extracted from the red seaweed Aghardhiella tenera against human immunodeficiency virus and other enveloped viruses. Antivir Chem Chemother 5: 297-303.

9. Luscher-Mattli M (2000) Polyanions--a lost chance in the fight against HIV and other virus diseases? Antivir Chem Chemother 11: 249-259.

10. Chung CS, Hsiao JC, Chang YS, Chang W (1998) A27L protein mediates vaccinia virus interaction with cell surface heparan sulfate. J Virol 72: 15771585.

11. Flexner C, Barditch-Crovo PA, Kornhauser DM, Farzadegan H, Nerhood LJ, et al. (1991) Pharmacokinetics, toxicity, and activity of intravenous dextran sulfate in human immunodeficiency virus infection. Antimicrob Agents Chemother 35: 2544-2550

12. Borowitzka MA (1995) Microalgae as sources of pharmaceuticals and other biologically active compounds. J Appl Phycol 7: 3-15.

13. Mayer AM, Hamann MT (2005) Marine pharmacology in 2001--2002: marine compounds with anthelmintic, antibacterial, anticoagulant, antidiabetic, antifungal, anti-inflammatory, antimalarial, antiplatelet, antiprotozoal, antituberculosis, and antiviral activities; affecting the cardiovascular, immune and nervous systems and other miscellaneous mechanisms of action. Comp Biochem Physiol C Toxicol Pharmacol 140: 265-286.

14. Singh S, Kate BN, Banerjee UC (2005) Bioactive compounds from cyanobacteria and microalgae: an overview. Crit Rev Biotechnol 25: 73-95.

15. Gustafson KR, Cardellina JH 2nd, Fuller RW, Weislow OS, Kiser RF, et al. (1989) AIDS-antiviral sulfolipids from cyanobacteria (blue-green algae). J Natl Cancer Inst 81: 1254-1258

16. Loya S, Reshef V, Mizrachi E, Silberstein C, Rachamim Y, et al. (1998) The inhibition of the reverse transcriptase of HIV-1 by the natural sulfoglycolipids from cyanobacteria: contribution of different moieties to their high potency. $J$ Nat Prod 61: 891-895.

17. Ohta K, Mizushina Y, Hirata N, Takemura M, Sugawara F, et al. (1998) Sulfoquinovosyldiacylglycerol, KM043, a new potent inhibitor of eukaryotic DNA polymerases and HIV-reverse transcriptase type 1 from a marine red alga, Gigartina tenella. Chem Pharm Bull (Tokyo) 46: 684-686.

18. Ohta K, Mizushina Y, Hirata N, Takemura M, Sugawara F, et al. (1999) Action of a new mammalian DNA polymerase inhibitor, sulfoquinovosyldiacylglycerol. Biol Pharm Bull 22: 111-116.

19. Balzarini J, Schols D, Neyts J, Van Damme E, Peumans W, et al. (1991) Alpha-(1-3)-and alpha-(1-6)-D-mannose-specific plant lectins are markedly inhibitory to human immunodeficiency virus and cytomegalovirus infections in vitro. Antimicrob Agents Chemother 35: 410-416.

20. Balzarini J, Neyts J, Schols D, Hosoya M, Van Damme E, et al. (1992) The mannose-specific plant lectins from Cymbidium hybrid and Epipactis helleborine and the ( $\mathrm{N}$-acetylglucosamine)n-specific plant lectin from Urtica dioica are potent and selective inhibitors of human immunodeficiency virus and cytomegalovirus replication in vitro. Antiviral Res 18: 191-207.

21. Balzarini J, Hatse S, Vermeire K, Princen K, Aquaro S, et al. (2004a) Mannose-specific plant lectins from the Amaryllidaceae family qualify as efficient microbicides for prevention of human immunodeficiency virus infection. Antimicrob Agents Chemother 48: 3858-3870.

22. Balzarini J, Van Laethem K, Hatse S, Vermeire K, De Clercq E, et al. (2004b) Profile of resistance of human immunodeficiency virus to mannose-specific plant lectins. J Virol 78: 10617-10627.

23. Barrientos LG, Gronenborn AM (2005) The highly specific carbohydratebinding protein cyanovirin-N: structure, anti-HIV/Ebola activity and possibilities for therapy. Mini Rev Med Chem 5: 21-31.

24. Dey B, Lerner DL, Lusso P, Boyd MR, Elder JH, et al. (2000) Multiple antiviral activities of cyanovirin- $\mathrm{N}$ : blocking of human immunodeficiency virus type $1 \mathrm{gp} 120$ interaction with CD4 and coreceptor and inhibition of diverse enveloped viruses. J Virol 74: 4562-4569.

25. Kolender AA, Pujol CA, Damonte EB, Matulewicz MC, Cerezo AS (1997) The system of sulfated alpha-(1-->3)-linked D-mannans from the red seaweed Nothogenia fastigiata: structures, antiherpetic and anticoagulant properties. Carbohydr Res 304: 53-60.

26. Hayashi T, Hayashi K, Maeda M, Kojima I (1996b) Calcium spirulan, an inhibitor of enveloped virus replication, from a blue-green alga Spirulina platensis. J Nat Prod 59: 83-87.

27. Lee JB, Hayashi T, Hayashi K, Sankawa U, Maeda M, et al. (1998) Further purification and structural analysis of calcium spirulan from Spirulina platensis. J Nat Prod 61: 1101-1104.

28. Lee JB, Srisomporn P, Hayashi K, Tanaka T, Sankawa U, et al. (2001) Effects of structural modification of calcium spirulan, a sulfated polysaccharide from Spirulina platensis, on antiviral activity. Chem Pharm Bull (Tokyo) 49: 108110.

29. Nakano JH, Esposito JJ (1989) in: Schmidt, NJ, Emmons, RW (Eds.), Diagnostic Procedures for Viral, rickettsial and chlamydial Infections. $6^{\text {th }}$ edition. American Public Health Association, Washington, DC, pp 1225.

30. World Health Organisation (1969) Guide to the Laboratory Diagnosis of Smallpox for Smallpox Eradication Programmes. Geneva: World Health Organization.

31. König T (2007) Gewinnung und Charakterisierung antiviraler Wirkstoffe aus aquatischen Mikroorganismen. Dissertation, Technische Fakultät der Universität Erlangen-Nürnberg, Germany.

32. Rechter S, König T, Auerochs S, Thulke S, Walter H, et al. (2006) Antiviral activity of Arthrospira-derived spirulan-like substances. Antiviral Res 72: 197 206.

33. Hayashi K, Hayashi T, Kojima I (1996a) A natural sulfated polysaccharide, calcium spirulan, isolated from Spirulina platensis: in vitro and ex vivo evaluation of anti-herpes simplex virus and anti-human immunodeficiency virus activities. AIDS Res Hum Retroviruses 12: 1463-1471.

34. Damonte EB, Matulewicz MC, Cerezo AS (2004) Sulfated seaweed polysaccharides as antiviral agents. Curr Med Chem 11: 2399-2419.

35. Richards JT, Kern ER, Glasgow LA, Overall JC Jr, Deign EF, et al. (1978) Antiviral activity of extracts from marine algae. Antimicrob Agents Chemother 14: $24-30$.

36. Walter C, Steinau T, Gerbsch N, Buchholz R (2003) Monoseptic cultivation of phototrophic microorganisms--development and scale-up of a photobioreactor system with thermal sterilization. Biomol Eng 20: 261-271. 